\title{
Evaluation of the effect of different growth media and incubation time on the suitability of biofilm formation by Pseudomonas aeruginosa and Streptococcus pyogenes
}

\author{
Mohammad A. Al-kafaween ${ }^{1}$, Abu Bakar Mohd Hilmi2* \\ 1 Faculty of Pharmacy, Department of Pharmacy, Al-Zaytoonah University of Jordan, Amman, Jordan \\ 2 Faculty of Health Sciences, Universiti Sultan Zainal Abidin, Terengganu, Malaysia
}

\begin{abstract}
Introduction: Biofilm formation has different stages and can be classified based on the bacterial strain, culture vessel, and the method employed. Biofilm formation is carried out in culture vessels to represent mode of infection in humans. Microbial concentration, growth medium, supplement, and incubation time are key factors to successfully form biofilm in a culture vessel. Objective: This study aimed to identify the optimum conditions for biofilm formation in a 96-well plate by culturing Pseudomonas aeruginosa and Streptococcus pyogenes. Materials and Methods: We utilized the infectious and pathogenic bacteria, $P$. aeruginosa and $S$. pyogenes strains. These bacteria were cultured in Mueller-Hinton Broth (MHB) and Tryptic Soy Broth (TSB) at two different optical densities (OD 0.05 and OD 0.1). After a certain incubation time, the formed biofilm was stained by using $0.1 \%$ crystal violet. The stained bacteria were disaggregated and measured using a microplate reader. Biofilm was then classified based on bacterial adherence to the plate. Results: Our results showed that $P$. aeruginosa and S. pyogenes biofilms were strongly formed on days 3 and 5 in MHB and TSB, respectively. However, the strongest biofilm formation was seen on day 3 after $P$. aeruginosa being incubated in MHB at OD 0.1 and after S. pyogenes being incubated in MHB at OD 0.05. Discussion: Biofilm formation is ranged between weak, moderate, and strong in accordance with the density of bacterial adhesion. Conclusion: P. aeruginosa and S. pyogenes biofilms were optimized at specific OD ( 0.1 and 0.05 , respectively) for 3 days cultivation in MHB.
\end{abstract}

Keywords: Biofilm, Mueller-Hinton Broth (MHB), Tryptic Soy Broth (TSB), Pseudomonas aeruginosa, Streptococcus pyogenes

Correspondence to: Abu Bakar Mohd Hilmi, Faculty of Health Sciences, Universiti Sultan Zainal Abidin, Terengganu, Malaysia;

E-mail: mhilmiab@unisza.edu.my

Received: November 13, 2021; Accepted: January 3, 2022; Published Online: February 10, 2022

Citation: Al-kafaween, M.A. and Hilmi A.B.M., 2022. Evaluation of the effect of different growth media and incubation time on the suitability of biofilm formation by Pseudomonas aeruginosa and Streptococcus pyogenes. Applied Environmental Biotechnology, 6(2): 19-26. http://doi.org/10.26789/AEB.2021.02.003 Copyright: Evaluation of the effect of different growth media and incubation time on the suitability of biofilm formation by Pseudomonas aeruginosa and Streptococcus pyogenes. (C) 2021 Mohammad A. Al-kafaween and Abu Bakar Mohd Hilmi. This is an Open Access article published by Urban Development Scientific Publishing Company. It is distributed under the terms of the Creative Commons Attribution-Noncommercial 4.0 International License, permitting all non-commercial use, distribution, and reproduction in any medium, provided the original work is properly cited and acknowledged.

\section{Introduction}

Bacteria commonly remain in a self-produced polymeric matrix and adhere to an inert or living surface (Jain et al., 2013). Microenvironment community of thousands of bacteria is known as the biofilm (Mohammad et al., 2020; Jadhav and Tale, 2015). Biofilm contains the colonized bacteria embedded in the amorphous extracellular material and is usually visualized as a thin layer, which is a unique feature to distinguish the free-living planktonic cells (Chua et al., 2014; Mohammad et al., 2021). The biofilm formation depends on multiple factors including mechanical aspects, organic chemistry, and the genome of the microorganism (Mohammad et al., 2020; Nyenje et al., 2013). Biofilm plays a vital role in the etiopathology of the diseases providing antibiotic resistance (H $\varphi$ iby et al., 2011). Anatomical and physiological features of bacteria support biofilm formation, e.g., flagella, fimbriae, and pili are crucial in developing a bridge between the bacteria and substrate. The downstream product of biofilm is the hydrated matrix extracellular polymeric substance (EPS) consisting of proteins, polyuronic acids, nucleic acids, and lipids (Al-Bakri and Mahmoud, 2019; Mohammad et al., 2020; Mangwani et al., 2012). Biofilm attachment, detachment, mechanical strength, antibiotic resistance, and exoenzymatic degradation activity are dependent on EPS (Tarawneh et al., 2021; Winkelstrter et al., 2014; Yang et al., 2011).

Streptococcus pyogenes is a species of facultative, grampositive bacteria made up of nonsporing, nonmotile cocci called group A streptococci (GAS) (Stevens, 2014). S. pyogenes is the most pathogenic bacteria and clinically important for human illness (Johansson et al., 2010). S. pyogenes is commensal in the nasopharynx of healthy individuals but is responsible for a wide range of diseases including ear infection, skin infection, acute streptococcal sore throat, scarlet fever, and puerperal fever (Tadesse and Alem, 2006). Reports 
suggest that the persisting existence of streptococci within human cells may develop resistance against host immune defense system and antibiotic treatment (Rohde and Cleary, 2016). Although penicillin, erythromycin, and tetracycline treatment failure have been reported, antibiotics are still preferred for streptococcal infections (Kataja et al., 2002), (Magnussen et al., 2016). Thus, further study is required to eradicate streptococcal infection. Pseudomonas aeruginosa is a common aerobic, gram-negative, and rod-shaped bacterium that belongs to the Pseudomonadaceae family (Mohammad et al., 2021; Palanisamy et al., 2014). It can persist within a wide range of temperatures between $37^{\circ} \mathrm{C}$ and $42^{\circ} \mathrm{C}$ (Wolska, 2008). Being a free-living organism, it is commonly found in soil, vegetation, water, marshes, and coastal marine habitats. About $4 \%-12 \%$ of the human population possess $P$. aeruginosa in the gastrointestinal tract (GIT) (Sharma et al., 2014). $P$. aeruginosa produces a variety of infectious pigments such as pyoverdin (yellow-green), pyorubin (red-brown), and pyocyanin (blue-green) (El-Fouly et al., 2015). Reducing its infection is a crucial aim in clinical setting.

Mueller-Hinton Broth (MHB) is an antimicrobial susceptibility testing medium composed of beef, dehydrated infusion from casein hydrolysate, and starch. MHB was initially developed as transparent agar and used as a cultivation medium for many species of pathogenic bacteria (Mueller and Hinton, 1941). It is widely used for biofilm formation by $P$. aeruginosa, $S$. pyogenes, and many other infectious microorganisms. MHB is recommended for antimicrobial susceptibility testing of most commonly encountered aerobic and facultative anaerobic bacteria (National Committee for Clinical Laboratory Standards, 2000). Tryptic Soy Broth (TSB) is recommended for the isolation and cultivation of various aerobic and facultative anaerobic bacteria. Soya bean casein digest medium is another name for TSB and is recommended by various pharmacopeias as sterility and microbial limit testing medium (MacFaddin, 1985). This medium is a highly nutritious and contains a digest of casein and peptic to provide amino acids and long-chain peptides for the growth of microorganisms. Dextrose and dibasic potassium phosphate serve as the buffer (carbohydrate source), whereas sodium chloride provides the osmotic balance for TSB. In human diseases, pathogenic bacteria, such as $P$. aeruginosa and $S$. pyogenes, are the initial colonizers in all main organs including tooth. Their interaction with the substrate facilitates the first biofilm formation as a plaque (Yadav and Prakash, 2017). Plaque formation requires pellicle formation and reversible adhesion that involves weak, long-range physicochemical interactions (Young et al., 2016). Interaction between cell surface-pellicle and higher adhesion-receptor mediates the biofilm attachment and adhesion among cells (Longo et al., 2014). P. aeruginosa and S. pyogenes biofilms are the primary infection in human illness. Therefore, we aimed to establish the formation of $P$. aeruginosa and $S$. pyogenes biofilms in vitro for future degradation and inhibition experiments.

\section{Materials and Methods}

\subsection{Bacterial growth}

P. aeruginosa (ATCC 10145) and S. pyogenes (ATCC 19615) purchased from Teraslab Saintifik (Malaysia) were used for biofilm formation. $P$. aeruginosa and $S$. pyogenes inoculum were prepared from stock culture by selecting three to five morphologically identical colonies and were suspended into 4-5 mL of sterile MHB and TSB in sterilized universal bottles. The inoculum was incubated at $37^{\circ} \mathrm{C}$ for 24 hours (Shehu et al., 2016), (Jibril et al., 2019), (Fatima et al., 2018).

\subsection{Biofilm assay}

A few single colonies were suspended in sterile MHB and TSB before incubation at $37^{\circ} \mathrm{C}$ for 24 hours. After incubation, the suspension of MHB and TSB was adjusted to OD 0.1 and 0.05 for each broth, respectively. Then, $200 \mu \mathrm{L}$ of adjusted bacterial suspension was transferred to microtiter plate. The negative control contained $200 \mu \mathrm{L}$ of broth without bacteria. $P$. aeruginosa and $S$. pyogenes biofilms were observed for their adherence to microtiter plate after 3, 5, and 7 days of incubation. At the end of incubation, the solution was discarded, and the well was washed three times with $200 \mu \mathrm{L}$ of phosphate-buffered saline to remove planktonic bacteria. The plates were air-dried and stained with $200 \mu \mathrm{L}$ of $1 \%$ crystal violet for $10 \mathrm{~min}$. The plates were carefully rinsed under running tap water to remove excess stain, airdried at room temperature before solubilizing the biofilm with $200 \mu \mathrm{L}$ of $95 \%$ ethanol. Biofilms were characterized using a microplate reader at $570 \mathrm{~nm}$ (Tecan Infinite 200 PRO, Austria). The experiments were performed in triplicate (Mohammad et al., 2021; Jaffar et al., 2016; Mohammad et al., 2020; Tarawneh et al., 2021).

\subsection{Biofilms analyses}

The following criteria were used to classify the different adherent strengths: strong adherent $[\mathrm{SA}=(4 \times \mathrm{ODC})<$ OD)], moderate adherent $[\mathrm{MA}=(2 \times \mathrm{ODC})<\mathrm{OD} \leq(4 \times$ ODC)], weak adherent [WA $=$ ODC $<$ OD $\leq(2 \times$ ODC $)]$, or nonadherent $[\mathrm{NA}=\mathrm{OD} \leq \mathrm{ODC})]$. ODC was referred to the density of the negative control (Al-kafaween et al., 2019; Al-kafaween et al., 2019a; Mohammad et al., 2021; Nyenje et al., 2013).

\subsection{Statistical analyses}

Quantitative analysis of biofilm formation was performed by using SPSS (version 20.0: IBM). Mean differences were determined by using an independent t-test. Statistical significance was set at $p<0.05$. 


\section{Results}

Figure 1 demonstrates the reproducibility of $P$. aeruginosa biofilm. On day 3, the biofilms strongly adhered to the plate after incubation with $\mathrm{MHB}=0.76 \pm 0.11$, MHB OD $0.1=$ $1.11 \notin 01$, TSB OD $0.05=0.830 .0$, and TSB OD 0.1 $=1.07$.02. On day 5 , the biofilms strongly adhered to the well; MHB OD $0.05=0.53 \notin 05$, MHB OD $0.1=0.67 \pm$ 0.04 , TSB OD $0.05=0.56 \pm 0.05$, and TSB OD $0.1=0.64$ \pm 0.09 . However, the adherence was lesser than the biofilms on day 3. On day 7, biofilms did not adhere to the well after incubation with MHB OD $0.05=0.05 \pm 0.0$, MHB OD 0.1 $=0.06 \pm 0.01, \mathrm{TSB}$ OD $0.05=0.05 \pm 0.0$, and TSB OD 0.1 $=0.06 \pm 0.01$.

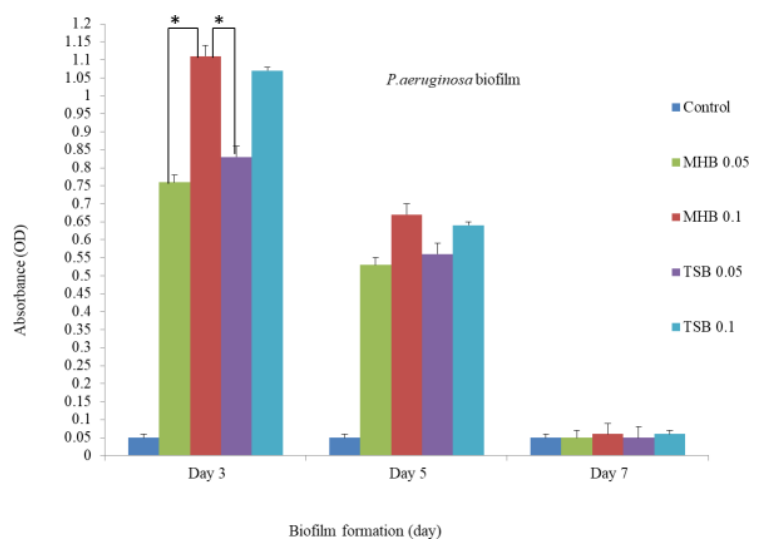

Figure 1. Effects of growth medium and optical density on biofilm formation by $P$. aeruginosa in MHB (OD 0.05 and 0.1 ) and TSB (OD 0.05 and 0.1 ). Asterisk $(*)$ indicates that independent t-test was significant $(p<0.05)$.

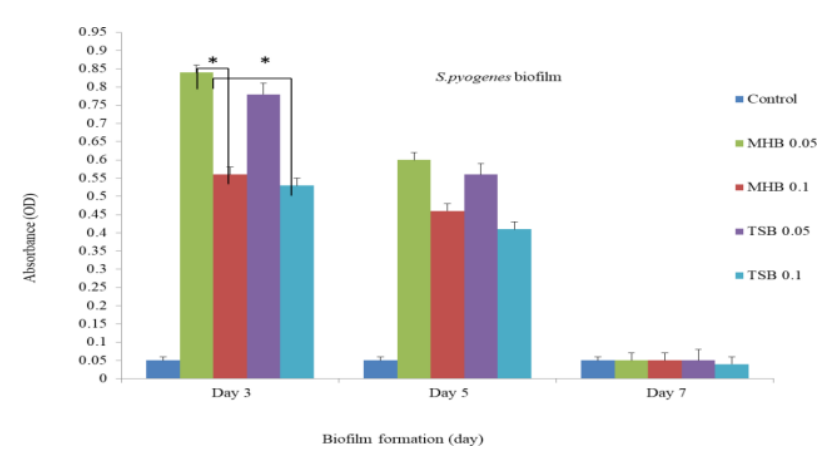

Figure 2. Effects of growth medium and optical density on biofilm formation by $S$. pyogenes in MHB (OD 0.05 and 0.1 ) and TSB (OD 0.05 and 0.1$)$. Asterisk $(*)$ indicates that independent t-test was significant $(p<0.05)$.

Figure 2 demonstrates the reproducibility of $S$. pyogenes biofilm. On day 3, biofilms strongly adhered to the plate after incubation with MHB OD $0.05=0.84 \pm 0.05$, MHB OD 0.1 $=0.56 \pm 0.07$, TSB OD $0.05=0.78 \pm 0.07$, and TSB OD $0.1=0.53 \pm 0.02$. On day 5 , the biofilms strongly adhered to the well; $\mathrm{MHB}$ OD $=0.6 \pm 0.02, \mathrm{MHB}$ OD $0.1=0.46$ \pm 0.03 , TSB OD $0.05=0.56 \pm 0.05$, and TSB OD $=0.41$ \pm 0.02 . However, the adherence was lesser than biofilms on day 3. On day 7, biofilms did not adhere to the well after incubation with MHB OD $0.05=0.05 \pm 0.01$, MHB OD 0.1 $=0.05 \pm 0.0, \mathrm{TSB}$ OD $0.05=0.05 \pm 0.01$, and TSB OD 0.1 $=0.04 \pm 0.0$.

Table 1 and Table 2 demonstrates the classification of biofilm formation by $P$. aeruginosa and $S$. pyogenes on mi-

Table 1. Classification of $P$. aeruginosa biofilms

\begin{tabular}{|c|c|c|c|c|c|}
\hline $\begin{array}{c}\text { Medium/ Initial } \\
\text { inoculum concentration }\end{array}$ & Control & Day 3 & Day 5 & Day 7 & $P$-value \\
\hline Parameters & Mean ODc \pm SD & Mean $\mathrm{OD} \pm \mathrm{SD}$ & Mean $\mathrm{OD} \pm \mathrm{SD}$ & Mean $\mathrm{OD} \pm \mathrm{SD}$ & $\begin{array}{c}\text { MHB } \mathrm{OD}_{600}(0.05) \text { compare with } \\
\text { TSB OD } \mathrm{OD}_{600}(0.05) \\
\text { No significance } \\
(\mathbf{0 . 0 8 9})\end{array}$ \\
\hline MHB OD $600(0.05)$ & $0.05 \pm 0.01$ & $\begin{array}{l}0.76 \pm 0.11 \\
(\text { SA) }\end{array}$ & $\begin{array}{l}0.53 \pm 0.05 \\
\quad(\mathbf{S A})\end{array}$ & $\begin{array}{l}0.05 \pm 0.0 \\
\quad(\text { NA) }\end{array}$ & $\begin{array}{c}\text { MHB OD } 600 \\
\text { TSB }(0.05) \text { compare with } \\
(\mathbf{0 . 0 1 3})\end{array}$ \\
\hline MHB OD $600(0.1)$ & $0.05 \pm 0.01$ & $\begin{array}{l}1.11 \pm 0.01 \\
(\mathbf{S A})\end{array}$ & $\begin{array}{l}0.67 \pm 0.04 \\
\quad(\text { SA })\end{array}$ & $\begin{array}{l}0.06 \pm 0.01 \\
\quad(\mathbf{N A})\end{array}$ & $\begin{array}{c}\text { MHB OD }_{600}(0.1) \text { compare with TSB } \\
\text { OD } 600_{60.05)} \\
(\mathbf{0 . 0 1 6})\end{array}$ \\
\hline TSB OD $600(0.05)$ & $0.05 \pm 0.01$ & $\begin{array}{l}0.83 \pm 0.07 \\
\quad(\mathbf{S A})\end{array}$ & $\begin{array}{l}0.56 \pm 0.05 \\
\quad(\mathbf{S A})\end{array}$ & $\begin{array}{l}0.05 \pm 0.0 \\
\text { (NA) }\end{array}$ & $\begin{array}{c}\text { MHB OD }_{600}(0.1) \text { compare with TSB } \\
\text { OD }_{600}(0.1) \\
\text { No significance } \\
(\mathbf{0 . 1 1 0})\end{array}$ \\
\hline \multirow[t]{2}{*}{ TSB OD $600(0.1)$} & $0.05 \pm 0.01$ & $\begin{array}{l}1.07 \pm 0.02 \\
(\text { SA })\end{array}$ & $\begin{array}{l}0.64 \pm 0.09 \\
\quad(\mathbf{S A})\end{array}$ & $\begin{array}{l}0.06 \pm 0.01 \\
\quad(\text { NA) }\end{array}$ & $\begin{array}{c}\text { TSB OD }_{600}(0.1) \text { compare with TSB } \\
\text { OD }_{600}(0.05) \\
(\mathbf{0 . 0 1 8})\end{array}$ \\
\hline & & & & & $\begin{array}{c}\text { MHB OD } 600(0.05) \text { compare with } \\
\text { MHB OD } 600(0.1) \\
(\mathbf{0 . 0 1 4})\end{array}$ \\
\hline
\end{tabular}

Note: Mueller Hinton Broth (MHB), Tryptic Soy Broth (TSB), Non-adherent (NA), Weakly adherent (WA), Moderately adherent (MA), Strongly adherent (SA), ODc (optical density for control), OD (optical density for test) 
Table 2. Classification of S. pyogenes biofilms

\begin{tabular}{|c|c|c|c|c|c|}
\hline $\begin{array}{c}\text { Medium/ Initial } \\
\text { inoculum concentration }\end{array}$ & Control & Day 3 & Day 5 & Day 7 & $P$-value \\
\hline Parameters & Mean ODc \pm SD & Mean $\mathrm{OD} \pm \mathrm{SD}$ & Mean $\mathrm{OD} \pm \mathrm{SD}$ & Mean $\mathrm{OD} \pm \mathrm{SD}$ & $\begin{array}{c}\text { MHB OD } 600(0.05) \text { compare with } \\
\text { TSB OD } 600(0.05) \\
\text { No significance } \\
(\mathbf{0 . 0 8 9})\end{array}$ \\
\hline MHB OD $600(0.05)$ & $0.05 \pm 0.01$ & $\begin{array}{l}0.76 \pm 0.11 \\
\quad(\text { SA })\end{array}$ & $\begin{array}{l}0.53 \pm 0.05 \\
\quad(\text { SA })\end{array}$ & $\begin{array}{l}0.05 \pm 0.0 \\
\quad(\mathbf{N A})\end{array}$ & $\begin{array}{c}\text { MHB OD } 600(0.05) \text { compare with } \\
\text { TSB OD }_{600}(0.1) \\
(\mathbf{0 . 0 1 3})\end{array}$ \\
\hline MHB OD $600(0.1)$ & $0.05 \pm 0.01$ & $\begin{array}{l}1.11 \pm 0.01 \\
(\text { SA })\end{array}$ & $\begin{array}{l}0.67 \pm 0.04 \\
\quad(\text { SA })\end{array}$ & $\begin{array}{l}0.06 \pm 0.01 \\
\quad(\mathbf{N A})\end{array}$ & $\begin{array}{c}\text { MHB OD } 600(0.1) \text { compare with TSB } \\
\text { OD } 600(0.05)^{(\mathbf{0 . 0 1 6})}\end{array}$ \\
\hline TSB OD $600(0.05)$ & $0.05 \pm 0.01$ & $\begin{array}{l}0.83 \pm 0.07 \\
\quad(\text { SA })\end{array}$ & $\begin{array}{l}0.56 \pm 0.05 \\
\quad(\text { SA })\end{array}$ & $\begin{array}{l}0.05 \pm 0.0 \\
\text { (NA) }\end{array}$ & $\begin{array}{c}\text { MHB OD }_{600}(0.1) \text { compare with TSB } \\
\text { OD } 600(0.1) \\
\text { No significance } \\
(\mathbf{0 . 1 1 0})\end{array}$ \\
\hline \multirow[t]{2}{*}{$\mathrm{TSB} \mathrm{OD}_{600}(0.1)$} & $0.05 \pm 0.01$ & $\begin{array}{c}1.07 \pm 0.02 \\
(\text { SA })\end{array}$ & $\begin{array}{l}0.64 \pm 0.09 \\
(\text { SA })\end{array}$ & $\begin{array}{l}0.06 \pm 0.01 \\
\quad(\mathbf{N A})\end{array}$ & $\begin{array}{c}\text { TSB OD } 600(0.1) \text { compare with TSB } \\
\text { OD } 600(0.05) \\
(\mathbf{0 . 0 1 8})\end{array}$ \\
\hline & & & & & $\begin{array}{c}\text { MHB } \mathrm{OD}_{600}(0.05) \text { compare with } \\
\text { MHB OD } \mathrm{OD}_{600}(0.1) \\
(\mathbf{0 . 0 1 4})\end{array}$ \\
\hline
\end{tabular}

Note: Mueller Hinton Broth (MHB), Tryptic Soy Broth (TSB), Non-adherent (NA), Weakly adherent (WA), Moderately adherent (MA), Strongly adherent (SA), ODc (optical density for control), OD (optical density for test)

crotiter plate after 3, 5, and 7 days of incubation with $\mathrm{MHB}$ OD 0.05, MHB OD 0.1, TSB OD 0.05, and TSB OD 0.1 . The biofilms adhered strongly to the plate on days 3 and 5 but did not adhere on day 7. As $P$. aeruginosa and $S$. pyogenes biofilms on day 3 have displayed the strongest adherence for both media and densities therefore, we further quantify statistically. The formation of $P$. aeruginosa biofilm in MHB OD 0.1 was significantly higher than MHB OD $0.05(p=0.014)$ and TSB OD $0.05(p=0.016)$. Meanwhile, the formation of $S$. pyogenes biofilm in MHB OD 0.05 was significantly higher than MHB OD $0.1(p=0.016)$ and TBS OD 0.1 ( $p=$ 0.019).

\section{Discussion}

This is the first comparative study between MHB OD 0.05, MHB OD 0.1, TSB OD 0.05, and TSB OD 600 (0.1) for biofilm formation by $P$. aeruginosa and $S$. pyogenes. Biofilm formation in microtiter plates is certainly the most commonly used method. Originally developed by Fletcher to investigate bacteria attachment (Azeredo et al., 2017; Fletcher, 1977), it further proved to be compatible with the study of sessile development (Azeredo et al., 2017). In the classical procedure, bacterial cells are grown in the wells of a microtiter plate (Djordjevic et al., 2002). At different time points, the wells are emptied and washed to remove planktonic cells before staining the biomass attached to the surface of the wells. Biofilm biomass can alternatively be quantified by detachment and subsequent plating (Azeredo et al., 2017). Biofilm producing bacteria are responsible for many recalcitrant infections and are notoriously difficult to eradicate. They exhibit resistance to antibiotics by various methods like restricted penetration of antibiotic into biofilms, decreased growth rate and expression of resistance genes (Lewis, 2001). There are various methods for biofilm detection (Aparna and Yadav, 2008; Donlan et al., 2001; Hassan et al., 2011). In this study, $P$. aeruginosa and $S$. pyogenes were evaluated by a microtiter plate method for their ability to form biofilms using both media (MHB and TSB) and ODs (OD $600 \quad 0.05$ and $\mathrm{OD}_{600}$ 0.1). P. aeruginosa biofilms on day three were significantly higher compared to days four, five and six. Similarly, S. pyogenes biofilms on day three were significantly higher compared to days four, five, and six. Thus, suggest that at day three, a large number of bacteria in the plate were switched to biofilm. An optimum number of bacteria adherence occurred in microtiter plate resulting strong biofilm formation on that day (Jama et al., 2017; Rossi et al., 2016). In addition to day three, this study indicates that the biofilm formation by $P$. aeruginosa and $S$. pyogenes were strong on days four, five and six. $P$. aeruginosa and $S$. pyogenes were not able to produce strong biofilm on days two and seven. Many factors such as integration of diverse signals from the environment might play a role in biofilm formation, concurrent with other events such as phenotypic and genetic switching during biofilm production and also EPS production (Bakar et al., 2018; Ismael, 2013). This study found that both bacteria are able to form biofilms by using MHB and TSB, but S. pyogenes biofilm was slightly higher in MHB than TSB. Biofilms can form until day five by using both media (MHB and TSB) at both ODs (OD 6000.05 and $\mathrm{OD}_{600}$ 0.1). Composition of medium has been documented to influence the ability of bacteria to produce biofilm under in vitro conditions. The presence of glucose in growth media has been reported to enhance biofilm formation (Stepanovi et al., 2000). Type of media, culture condition and surface of ves- 
sel cultivation are significantly robust the biofilm formation (Hood and Zottola, 1997; Iversen et al., 2004). The ability to adhere to a solid surface and the consecutive formation of an organised bacterial biofilm community are crucial for the formation of $P$. aeruginosa and $S$. pyogenes biofilms. This is because the formation of biofilm depends on the ability of bacteria to attach in the surface for 96-well plate (Merritt et al., 2011). It is well known that the switching from a planktonic to a biofilm mode of growth is an intricate process, which occurs in response of environmental changes. As the first step of biofilm formation is bacterial adhesion to surface, this study hypothesis that the strains showed a high ability to create hydrophobic interactions with the microtiter plate surface (Woo et al., 2012). Moreover, physical and chemical plate properties are the main factor that regulate the initial adhesion process (Lemos et al., 2014).

Comparison between Mueller-Hinton Broth (MHB) and Tryptic Soy Broth (TSB) for Pseudomonas aeruginosa and Streptococcus pyogenes biofilm formatio Recognition of the fact that bacterial biofilm may play a role in the pathogenesis of disease has led to an increased focus on identifying diseases that may be biofilm-related. Biofilm infections are typically chronic in nature, as biofilm-residing bacteria can be resilient to both the immune system, antibiotics, and other treatments (Vestby et al., 2020). In most cases reviewed, the biofilms were identified through various imaging technics, in addition to other study approaches. Biofilm being a mere reservoir of pathogenic bacteria, to playing a more active role, e.g., by contributing to inflammation. Observations also indicate that biofilm does not exclusively occur extracellularly, but may also be formed inside living cells. Furthermore, the presence of biofilm may contribute to development of cancer (Vestby et al., 2020). Commonly, biofilm formation is influenced by cell motility particularly when it is mediated by flagella. Under certain environmental conditions, flagella is necessary for biofilm formation by $P$. aeruginosa (Priya and Brundha, 2013). However, the rapid decrease of biofilm-forming capacity that observed on day seven could be attributed to the loss of exopolymers from the biofilm and in particular of exopolysaccharides, which may suggest that an active process of detachment was occurring, probably mediated by enzymatic degradation (Allison et al., 1998). Biofilms can be found almost anywhere and may impact human health both positively and negatively. One example of a positive effect includes the biofilms of commensal bacteria such as $S$. pyogenes and $S$. epidermidis, which can impede the colonisation of potentially pathogenic bacteria through the stimulation of host-cell immune defences and the prevention of adhesion (Gupta et al., 2016; Vestby et al., 2020). Due to the widespread distribution of biofilms in diseases and their resilience to numerous antimicrobial treatments, biofilm research is receiving more attention. Owing to increasing antimicrobial resistance, the focus of current research is shifting from targeting bacterial growth/division that causes cell death or dormancy, towards novel approaches (Archer et al.,
2011).

Previous study showed that $P$. aeruginosa produced a great biofilm on day three (Culotti and Packman, 2014). Another study found that day three was the preferable day in producing strong biofilm by Proteus mirabilis (Emineke et al., 2017). A study in 2001 showed that an ideal cultivation period for producing biofilms by Candida albicans was at 72 hours and Saccharomyces cerevisiae was at 60 hours (Chandra et al., 2001). Previous study reported that Escherichia coli produced a strong biofilm on day 3 and 5 (Al-kafaween et al., $2019 b$ ). Study by (Jaffar et al., 2016) reported that day 2 was the preferable incubation duration to produce biofilm in $A$. actinomycetemcomitans and day 7 for $P$. gingivalis. Previous studies have indicated that temperature, nutrients and other components in media affected the attachment of microorganisms to the surfaces of various materials (Hood and Zottola, 1997; Iversen et al., 2004). Study by (Al-kafaween et al., 2019b) showed that the E. coli produced biofilm on day 3 and day 5 in Brain heart infusion (BHI) and Luria broth (LB) at OD 0.05 and OD 0.1 (Al-kafaween et al., 2019). Studies have used TSB for Staphylococcus and Pseudomonas species but this depends on growing condition of microorganisms and optical density (Nyenje et al., 2013; Stepanovi et al., 2000). Meanwhile, P. aeruginosa and Klebsiella pneumonia have been reported to produce strong biofilm formation in TSB in different $\mathrm{pH}$ and different temperatures (Hoštacká et al., 2010). Previous study demonstrated that the $S$. epidermidis had produced biofilm on day 3 and 5 in MHB and TSB at OD 0.05 and OD 0.1 (Al-kafaween et al., 2019b). This study suggests that as non-motile bacteria, S. pyogenes are able to form strong biofilm with very minimum number of CFU. On the other hand, $P$. aeruginosa is a motile bacterium prefers more cells for biofilm formation. However, both concentration of OD 0.05 and OD 0.1 are ranged as lower concentration of CFU. Lower concentration is the best start for biofilm maturation because it provides enough attachment space for planktonic cells (Jaffar et al., 2016). However, in this study selected the suitable media based on the highest value of biofilm formation after the measurement of wavelength was obtained regardless the level of inoculum. However, based on our findings, MHB is most suitable for biofilm formation by $P$. aeruginosa and $S$. pyogenes. The type of media, culture condition, and surface of vessel cultivation are significant factors affecting robust biofilm formation. Composition of the medium can also influence the ability of bacteria to produce biofilm under in vitro conditions.

\section{Conclusion}

Incubation time, growth medium, and OD can significantly affect the formation of $P$. aeruginosa and $S$. pyogenes biofilms. We found that the formation of biofilm by $P$. aeruginosa and $S$. pyogenes successfully occurred on day 3 . MHB is a suitable medium for $P$. aeruginosa and $S$. pyogenes biofilms. Both of these bacteria successfully formed biofilms at lower cell 
density such that for $P$. aeruginosa and $S$. pyogenes were 0.1 and 0.05 , respectively. We suggest that the specific medium (MHB) and lower cell concentration should be used for formation of strong biofilm by these bacteria and may further facilitate future biofilm research.

\section{Acknowledgments}

This work was supported by grant: UniSZA/2018/DPU/13: R0034-R013. The authors thank staff members of the Faculty of Health Sciences and Microbiology Laboratory at Universiti Sultan Zainal Abidin (UniSZA).

\section{Conflict of Interest}

The authors declare that there is no conflict of interest regarding the publication of this article.

\section{Author Contributions}

All authors made substantial contributions to conception and design, acquisition of data, or analysis and interpretation of data.

\section{References}

Al-Bakri, A.G. and Mahmoud, N.N., 2019. Photothermal-induced antibacterial activity of gold nanorods loaded into polymeric hydrogel against Pseudomonas aeruginosa biofilm. Molecules, 24(14), 2661. https://doi.org/10.3390/molecules24142661

Al-Kafaween, M.A., Hilmi, A.B.M., Al-Jamal, H.A.N., Elsahoryi, N.A., Jaffar, N. and Zahri, M.K., 2020. Pseudomonas aeruginosa and Streptococcus pyogenes Exposed to Malaysian Trigona Honey In Vitro Demonstrated Downregulation of Virulence Factor. Iranian Journal of Biotechnology, 18(4), e2542.

Al-kafaween, M.A., Hilmi, A.B.M., Al-Jamal, H.A.N., Jaffar, N., AlSayyed, H. and Zahri, M.K., 2021. Effects of Selected Malaysian Kelulut Honey on Biofilm Formation and the Gene Expression Profile of Staphylococcus Aureus, Pseudomonas aeruginosa and Escherichia Coli. Jordan Journal of Pharmaceutical Sciences, 14(1).

Al-kafaween, M.A., Hilmi, A.B.M., Jaffar, N., Al-Jamal, H.A.N. and Zahri, M.K., 2019. Determination of optimum incubation time for formation of Pseudomonas aeruginosa and Streptococcus pyogenes biofilms in microtiter plate. Bulletin of the National Research Centre, 43(1), 1-5. https://doi.org/10.1186/s42269-019-0131-9

Al-kafaween, M.A., Hilmi, A.B.M., Jaffar, N., Al-Jamal, H.A.N., Zahri, M.K. and Jibril, F.I., 2020. Antibacterial and Antibiofilm activities of Malaysian Trigona honey against Pseudomonas aeruginosa ATCC 10145 and Streptococcus pyogenes ATCC 19615. Jordan Journal of Biological Sciences, 13(1), 69 - 76.

AL-Kafaween, M.A., Khan, R.S., Hilmi, A.B.M. and Ariff, T.M., 2019a. Characterization of biofilm formation by Escherichia coli: An in vitro study. Journal of Applied Biology \& Biotechnology, 7(03), 17-19. https://doi.org/10.7324/JABB.2019.70304

AL-Kafaween, M.A., Khan, R.S., Hilmi, A.B.M. and Ariff, T.M., 2019 b. Characterization of biofilm formation by Escherichia coli: An in vitro study. Journal of Applied Biology \& Biotechnology, 7(03), 17-19. https://doi.org/10.7324/JABB.2019.70304
Al-kafaween, M.A., Mohd Hilmi, A.B., Jaffar, N., Nagi Al-Jamal, H.A., Zahri, M.K., Amonov, M., Elsahoryi, N.A., 2020. Effects of Trigona honey on the Gene Expression Profile of Pseudomonas aeruginosa ATCC 10145 and Streptococcus pyogenes ATCC 19615. Jordan Journal of Biological Sciences, 13(2).

Allison, D.G., Ruiz, B., SanJose, C., Jaspe, A. and Gilbert, P., 1998. Extracellular products as mediators of the formation and detachment of Pseudomonas fluorescens biofilms. FEMS Microbiology Letters, 167(2), $179-184$. https://doi.org/10.1111/j.1574-6968.1998.tb13225.x

Aparna, M.S. and Yadav, S., 2008. Biofilms: microbes and disease. Brazilian Journal of Infectious Diseases, 12(6), 526-530. https://doi.org/10.1590/S1413-86702008000600016

Archer, N.K., Mazaitis, M.J., Costerton, J.W., Leid, J.G., Powers, M.E. and Shirtliff, M.E., 2011. Staphylococcus aureus biofilms: properties, regulation, and roles in human disease. Virulence, 2(5), 445-459. https://doi.org/10.4161/viru.2.5.17724

Azeredo, J., Azevedo, N.F., Briandet, R., Cerca, N., Coenye, T., Costa, A. R., Jaglic, Z., 2017. Critical review on biofilm methods. Critical Reviews in Microbiology, 43(3), 313-351. https://doi.org/10.1080/1040841X.2016.1208146

Bakar, M.A., McKimm, J., Haque, S.Z., Majumder, M.A.A. and Haque, M., 2018. Chronic tonsillitis and biofilms: a brief overview of treatment modalities. Journal of Inflammation Research, 11, 329. https://doi.org/10.2147/JIR.S162486

Chandra, J., Kuhn, D.M., Mukherjee, P.K., Hoyer, L.L., McCormick, T. and Ghannoum, M.A., 2001. Biofilm formation by the fungal pathogenCandida albicans: development, architecture, and drug resistance. Journal of Bacteriology, 183(18), 5385-5394. https://doi.org/10.1128/JB.183.18.5385-5394.2001

Chua, S.L., Liu, Y., Yam, J.K.H., Chen, Y., Vejborg, R.M., Tan, B.G.C., Yang, L., 2014. Dispersed cells represent a distinct stage in the transition from bacterial biofilm to planktonic lifestyles. Nature Communications, 5,4462 . https://doi.org/10.1038/ncomms5462

Culotti, A. and Packman, A.I., 2014. Pseudomonas aeruginosa promotes Escherichia coli biofilm formation in nutrient-limited medium. PloS One, 9(9), e107186. https://doi.org/10.1371/journal.pone.0107186

Djordjevic, D., Wiedmann, M. and McLandsborough, L., 2002. Microtiter plate assay for assessment of Listeria monocytogenes biofilm formation. Applied and Environmental Microbiology, 68(6), 2950-2958. https://doi.org/10.1128/AEM.68.6.2950-2958.2002

Donlan, R., Murga, R., Bell, M., Toscano, C., Carr, J., Novicki, T., Miller, J., 2001. Protocol for detection of biofilms on needleless connectors attached to central venous catheters. Journal of Clinical Microbiology, 39(2), 750-753. https://doi.org/10.1128/JCM.39.2.750-753.2001

El-Fouly, M., Sharaf, A., Shahin, A., El-Bialy, H.A. and Omara, A., 2015. Biosynthesis of pyocyanin pigment by Pseudomonas aeruginosa. Journal of Radiation Research and Applied Sciences, 8(1), 36-48. https://doi.org/10.1016/j.jrras.2014.10.007

Emineke, S., Cooper, A.J., Fouch, S., Birch, B.R. and Lwaleed, B.A., 2017. Diluted honey inhibits biofilm formation: potential application in urinary catheter management? Journal of Clinical Pathology, 70(2), 140-144. https://doi.org/10.1136/jclinpath-2015-203546

Fletcher, M., 1977. The effects of culture concentration and age, time, and temperature on bacterial attachment to polystyrene. Canadian Journal of Microbiology, 23(1), 1-6. https://doi.org/10.1139/m77-001

Gupta, P., Sarkar, S., Das, B., Bhattacharjee, S. and Tribedi, P., 2016. Biofilm, pathogenesis and prevention-a journey to break the wall: a review. Archives of Microbiology, 198(1), 1-15. https://doi.org/10.1007/s00203-015-1148-6

Hassan, A., Usman, J., Kaleem, F., Omair, M., Khalid, A. and Iqbal, M., 2011. Evaluation of different detection methods of biofilm formation in the clinical isolates. Brazilian Journal of Infectious Diseases, 15(4), 305-311. https://doi.org/10.1016/S1413-8670(11)70197-0 
H $\varphi$ iby, N., Ciofu, O., Johansen, H.K., Song, Z.J., Moser, C., Jensen, P. $\varnothing$, Bjarnsholt, T., 2011. The clinical impact of bacterial biofilms. International Journal of Oral Science, 3(2), 55. https://doi.org/10.4248/IJOS11026

Hood, S.K. and Zottola, E.A., 1997. Growth media and surface conditioning influence the adherence of Pseudomonas fragi, Salmonella typhimurium, and Listeria monocytogenes cells to stainless steel. Journal of Food Protection, 60(9), 1034-1037. https://doi.org/10.4315/0362-028X-60.9.1034

Hoštacká, A., Čižnár, I. and Štefkovičová, M., 2010. Temperature and pH affect the production of bacterial biofilm. Folia Microbiologica, 55(1), 75-78. https://doi.org/10.1007/s12223-010-0012-y

Fatima, I.J., Mohd Hilmi A.B., Salwani, I., Lavaniya, M., 2018. Physicochemical Characteristics of Malaysian Stingless Bee Honey from Trigona Species. International Medical Journal Malaysia, 17. https://doi.org/10.31436/imjm.v17i1.1030

Ismael, N.F., 2013. "Vinegar" as Anti-bacterial Biofilm formed by Streptococcus pyogenes Isolated from Recurrent Tonsillitis Patients, in vitro. Jordan Journal of Biological Sciences, 147(898), 1-7. https://doi.org/10.12816/0001532

Iversen, C., Lane, M. and Forsythe, S., 2004. The growth profile, thermotolerance and biofilm formation of Enterobacter sakazakii grown in infant formula milk. Letters in Applied Microbiology, 38(5), 378-382. https://doi.org/10.1111/j.1472-765X.2004.01507.x

Jadhav, A.T. and Tale, V.S., 2015. Isolation and characterization of biofilm forming Streptococcus species from oral flora of cancer patients. International Journal of Current Microbiology and Applied Science, 38-47.

Jaffar, N., Miyazaki, T. and Maeda, T., 2016. Biofilm formation of periodontal pathogens on hydroxyapatite surfaces: Implications for periodontium damage. Journal of Biomedical Materials Research, 104(11), $2873-$ 2880

https://doi.org/10.1002/jbm.a.35827

Jain, K., Parida, S., Mangwani, N., Dash, H.R. and Das, S., 2013. Isolation and characterization of biofilm-forming bacteria and associated extracellular polymeric substances from oral cavity. Annals of Microbiology, 63(4), 1553-1562. https://doi.org/10.1007/s13213-013-0618-9

Jama, C., Abdallah, M., Boukherroub, R., Faille, C. and Chihib, N.-E., 2017. Effect of incubation duration, growth temperature, and abiotic surface type on cell surface properties, adhesion and pathogenicity of biofilm-detached Staphylococcus aureus cells. AMB Express, 7(1), 191. https://doi.org/10.1186/s13568-017-0492-0

Jibril, F.I., Hilmi, A.B.M. and Manivannan, L., 2019. Isolation and characterization of polyphenols in natural honey for the treatment of human diseases. Bulletin of the National Research Centre, 43(1), 4. https://doi.org/10.1186/s42269-019-0044-7

Johansson, L., Thulin, P., Low, D.E. and Norrby-Teglund, A., 2010. Getting under the skin: the immunopathogenesis of Streptococcus pyogenes deep tissue infections. Clinical Infectious Diseases, 51(1), 58-65. https://doi.org/10.1086/653116

Kataja, J., Huovinen, P., Efstratiou, A., Perez-Trallero, E., Seppl, H. and Group, M.R.S., 2002. Clonal relationships among isolates of erythromycin-resistant Streptococcus pyogenes of different geographical origin. European Journal of Clinical Microbiology and Infectious Diseases, 21(8), 589-595. https://doi.org/10.1007/s10096-002-0771-8

Lemos, M., Borges, A., Teodsio, J., Arajo, P., Mergulho, F., Melo, L. and Simes, M., 2014. The effects of ferulic and salicylic acids on Bacillus cereus and Pseudomonas fluorescens single-and dual-species biofilms. International Biodeterioration \& Biodegradation, 86, 42-51. https://doi.org/10.1016/j.ibiod.2013.06.011

Lewis, K., 2001. Riddle of biofilm resistance. Antimicrobial Agents and Chemotherapy, 45(4), 999-1007. https://doi.org/10.1128/AAC.45.4.999-1007.2001

Longo, F., Vuotto, C. and Donelli, G., 2014. Biofilm formation in Acinetobacter baumannii. New Microbiol, 37(2), 119-127.

MacFaddin, J., 1985. Media for Isolation-Cultivation-IdentificationMaintenance of Medical Bacteria, Vol. 1, Williams and Wilkins, Baltimore Disclaimer: User must ensure suitability of the product (s) in their application prior to use.
Magnussen, M.D., Gaini, S., Gislason, H. and Kristinsson, K.G., 2016. Antibacterial resistance in Streptococcus pyogenes (GAS) from healthy carriers and tonsillitis patients and association with antibacterial sale in the Faroe Islands. Apmis. https://doi.org/10.1111/apm.12513

Mangwani, N., Dash, H.R., Chauhan, A. and Das, S., 2012. Bacterial quorum sensing: functional features and potential applications in biotechnology. Journal of Molecular Microbiology and Biotechnology, 22(4), 215-227.

https://doi.org/10.1159/000341847

Merritt, J.H., Kadouri, D.E. and OToole, G.A., 2011. Growing and analyzing static biofilms. Current Protocols in Microbiology, 22(1), $1 \mathrm{~B}$. 1.1-1B. 1.18. https://doi.org/10.1002/9780471729259.mc01b01s22

Mohammad A. Al-kafaween, A.B.M.H., Hamid A. Nagi Al-Jamal, Rania M. Al-Groom, Nour A. Elsahoryi and Al-Sayyed, H., 2021. Potential Antibacterial Activity Of Yemeni Sidr Honey Against Pseudomonas aeruginosa And Streptococcus pyogenes. Anti-Infective Agents, 19(4), $1-15$. https://doi.org/10.2174/2211352519666210319100204

Mohammad A. Al-kafaween, A.B.M.H., Hamid Ali Nagi Al-Jamal., 2021. The Beneficial Effects of Stingless Bee Kelulut Honey Against Pseudomonas aeruginosa and Streptococcus pyogenes Planktonic and Biofilm. Tropical Journal of Natural Product Research, 5(10), 17881796. https://doi.org/10.26538/tjnpr/v5i10.15

Mohammad A. Al-kafaween , H.A.N.A.-J., Abu Bakar Mohd Hilmi , Nour Amin Elsahoryi , Norzawani Jaffar, Mohd Khairi Zahri., 2020. Antibacterial properties of selected Malaysian Tualang honey against Pseudomonas aeruginosa and Streptococcus pyogenes. Iranian Journal of microbiology, 12(6), 565-576. https://doi.org/10.18502/ijm.v12i6.5031

Mueller, J.H. and Hinton, J., 1941. A protein-free medium for primary isolation of the gonococcus and meningococcus. Proceedings of the Society for Experimental Biology and Medicine, 48(1), 330-333. https://doi.org/10.3181/00379727-48-13311

Nyenje, M.E., Green, E. and Ndip, R.N., 2013. Evaluation of the effect of different growth media and temperature on the suitability of biofilm formation by Enterobacter cloacae strains isolated from food samples in South Africa. Molecules, 18(8), 9582-9593. https://doi.org/10.3390/molecules18089582

Palanisamy, N.K., Ferina, N., Amirulhusni, A.N., Mohd-Zain, Z., Hussaini, J., Ping, L.J. and Durairaj, R., 2014. Antibiofilm properties of chemically synthesized silver nanoparticles found against Pseudomonas aeruginosa. Journal of Nanobiotechnology, 12(1), 2. https://doi.org/10.1186/1477-3155-12-2

Priya, S. and Brundha, S., 2013. Biofilm Formation by Streptococcus Serotypes on Dental Plaques.

Rohde, M. and Cleary, P.P., 2016. Adhesion and invasion of Streptococcus pyogenes into host cells and clinical relevance of intracellular streptococci.

Rossi, C., Chaves-Lpez, C., Serio, A., Goffredo, E., Goga, B.T.C. and Paparella, A., 2016. Influence of incubation conditions on biofilm formation by Pseudomonas fluorescens isolated from dairy products and dairy manufacturing plants. Italian Journal of Food Safety, 5(3). https://doi.org/10.4081/ijfs.2016.5793

Sharma, G., Rao, S., Bansal, A., Dang, S., Gupta, S. and Gabrani, R., 2014. Pseudomonas aeruginosa biofilm: potential therapeutic targets. Biologicals, 42(1), 1-7. https://doi.org/10.1016/j.biologicals.2013.11.001

Shehu, A., Ismail, S., Rohin, M.A.K., Harun, A., Aziz, A.A. and Haque, M., 2016. Antifungal Properties of Malaysian Tualang Honey and Stingless Bee Propolis against Candida albicans and Cryptococcus neoformans. Journal of Applied Pharmaceutical Science, 6(2), 44-50 https://doi.org/10.7324/JAPS.2016.60206

Stepanovi, S., Vukovi, D., Daki, I., Savi, B. and vabi-Vlahovi, M., 2000. A modified microtiter-plate test for quantification of staphylococcal biofilm formation. Journal of Microbiological Methods, 40(2), 175-179. https://doi.org/10.1016/S0167-7012(00)00122-6 
Stevens, D.L., 2014. Streptococcus pyogenes: group A 6-hemolytic Streptococcus.

Tadesse, A. and Alem, M., 2006. Medical Bacteriology. University of Gondar.

Tarawneh, O., Alwahsh, W., Abul-Futouh, H., Al-Samad, L.A., Hamadneh, L., Abu Mahfouz, H. and Fadhil Abed, A., 2021. Determination of Antimicrobial and Antibiofilm Activity of Combined LVX and AMP Impregnated in p(HEMA) Hydrogel. Applied Sciences, 11(18), 8345. https://doi.org/10.3390/app11188345

Vestby, L.K., Grnseth, T., Simm, R. and Nesse, L.L., 2020. Bacterial biofilm and its role in the pathogenesis of disease. Antibiotics, $9(2), 59$ https://doi.org/10.3390/antibiotics9020059

Winkelstrter, L.K., dos Reis Teixeira, F.B., Silva, E.P., Alves, V.F. and De Martinis, E.C.P., 2014. Unraveling microbial biofilms of importance for food microbiology. Microbial Ecology, 68(1), 35-46. https://doi.org/10.1007/s00248-013-0347-4

Wolska, K., 2008. Identification of AmpC B-lactamases in Clinical Pseu- domonas aeruginosa Strains. Advances in Clinical and Experimental Medicine, 17 (5): 519-523

Woo, J.H., Kim, S.T., Kang, I.G., Lee, J.H., Cha, H.E. and Kim, D.Y., 2012. Comparison of tonsillar biofilms between patients with recurrent tonsillitis and a control group. Acta Oto-laryngologica, 132(10), 11151120 .

https://doi.org/10.3109/00016489.2012.689859

Yadav, K. and Prakash, S., 2017. Dental Caries: A Microbiological Approach. Journal of Clinical Infectious Diseases \& Practice, 2(118), 2. https://doi.org/10.4172/2476-213X.1000118

Yang, L., Liu, Y., Wu, H., Hiby, N., Molin, S. and Song, Z.-j., 2011. Current understanding of multi-species biofilms. International Journal of Oral Science, 3(2), 74-81. https://doi.org/10.4248/IJOS11027

Young, C., Holder, R.C., Dubois, L. and Reid, S.D., 2016. Streptococcus pyogenes biofilm. 